\title{
Influence of reducing agents on optical properties of reduced graphene oxide
}

\author{
C. K. Manna ${ }^{1}$ and A. K. Chakraborty ${ }^{1,2^{*}}$ \\ ${ }^{1}$ Department of Physics, NIT Durgapur, Durgapur-713209, India \\ ${ }^{2}$ Centre of Excellence in Advanced Materials, NIT Durgapur, Durgapur-713209, India \\ *Email: amitkc61@gmail.com
}

Since 2004, graphene has become the most popular member of all carbon derivatives due to its two dimensional structure combined with exciting electronic optical, thermal and mechanical properties, which make it suitable for a number of applications such as sensors, supercapacitors, and epoxy based composites [1-3]. Consequently, synthesis of graphene and its derivatives such as graphene oxide (GO), reduced graphene oxide (rGO), etc. has attracted great attention of the researchers as it offers the potential to tune the electronic structure and in turn, the optical and electrical properties of graphene.

In this work, we report the synthesis of rGO by chemical reduction of GO using various reducing agents. The GO was synthesised following a modified recipe based on Hummer's method [4]. The microstructure and morphology of the rGO thus produced were characterised using powder x-ray diffraction (XRD) and field emission scanning electron microscopy. The optical properties were measured using UV-vis absorption, Infrared (FTIR) and photoluminescence spectroscopies.

The XRD plot (Figure 1, left panel) shows a prominent peak at $11.2^{\circ}$ corresponding to (001) plane of GO. Upon reduction by aniline, GO became rGO, which is evident by the absence of the peak at $11.2^{\circ}$. A new peak appears at $25.8^{\circ}$ which originates from the (002) graphitic planes in rGO. FESEM image in Figure 1 (right) clearly shows wellseparated GO flakes.

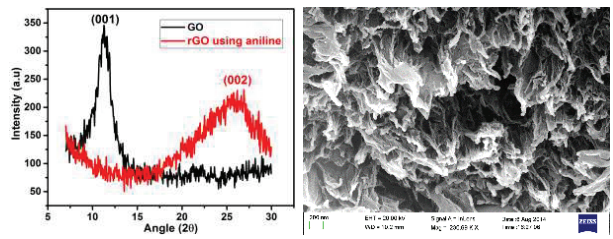

Figure 1: X-ray diffractogram (left) and FESEM image of GO (right)

$\mathrm{UV}-\mathrm{Vis}$ absorbance spectrum (Figure 2, left) was recorded in the range of 200 to $800 \mathrm{~nm}$. The graph shows two characteristic peaks in the absorbance spectrum of GO at 228 and $305 \mathrm{~nm}$ respectively. The prominent one appears at $228 \mathrm{~nm}$ which corresponds to a $\pi-\pi^{*}$ transition while a small hump at $\sim 305 \mathrm{~nm}$, corresponds to $n-\pi^{*}$ transition [5]. The bandgap of GO was also calculated from the absorbance spectrum (shown in the inset of absorbance spectrum) and it was found to be about $4.4 \mathrm{eV}$ using the Tauc equation.
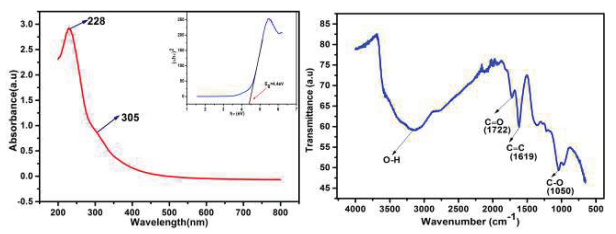

Figure 2: UV-Vis absorbance (left) and FTIR (right) spectra of GO

FTIR spectrum (Figure 2, right) of GO shows characteristic absorption bands corresponding to the epoxy $(\mathrm{C}-\mathrm{O}-\mathrm{C})$ stretching vibrations $\left(1050 \mathrm{~cm}^{-1}\right)$, carbonyl groups $(\mathrm{C}=\mathrm{O})$ of carboxylic derivatives stretching frequency $\left(1722 \mathrm{~cm}^{-1}\right)$. The bands around $3400 \mathrm{~cm}^{-1}$ and $1362 \mathrm{~cm}^{-1}$ can be assigned to the stretching and bending vibrations of $-\mathrm{OH}$ groups in GO respectively and the absorption near 1619 $\mathrm{cm}^{-1}$ is for $\mathrm{C}=\mathrm{C}$ stretch [5].

Further investigations are in progress in order to study the influence of different reducing agents on the UV-Vis absorbance and FTIR spectra of rGO and to draw a comparison with that of GO. We are also investigating the photoluminescence properties of GO and the effect of reducing agents on the photoluminescence of rGO, the results of which will be presented during the conference.

\section{References}

1. S. Gupta Chatterjee, S. Chatterjee, A. K. Ray, A. K. Chakraborty, Sens. Actuat. B 221 (2015) 1170

2. N. Chakrabarty, S. Sivaprakash, A. K. Chakraborty, AIP Conf. Proc. 1665 (2015) 050072

3. Li, W., Dichiara, A., Bai, J, Compos. Sci. Technol. 74 (2013) 221

4. W.S. Hummers, R.E. Offeman, J. Am. Chem. Soc. 80 (1958) 1339

5. V. Meriga, V. Sreeramulu, S. Sundaresan, C. Cahill, V. R. Dhanak, A. K. Chakraborty, J. Appl. Polym. Sci. 132 (2015) 42766 